\title{
EDITORIAL
}

\section{Laboratory Investigation editorial internship program}

\author{
Gene P Siegal ${ }^{1}$ and Catherine Ketcham ${ }^{2}$ \\ Laboratory Investigation (2011) 91, 646; doi:10.1038/labinvest.2011.65
}

${ }^{1}$ Department of Pathology, Division of Anatomic Pathology, University of Alabama at Birmingham, Birmingham, AL, USA and ${ }^{2} 5075$ Harbour Ridge Drive, Alpharetta, GA, USA.

Correspondence

should be addressed to (GP Siegal):

labinvest@comcast.net

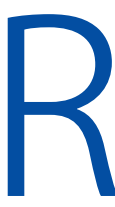
eviewing manuscripts is a critical activity in the maturation process of academic pathologists and pathobiologists. Laboratory Investigation has therefore developed an Editorial Internship Program to train young scientists to develop expertize in reviewing manuscripts. Associate Editors for the journal and select pathology chairs were asked to identify promising graduate students, postdocs, senior residents or starting faculty members who would be interested in reviewing manuscripts as Editorial Interns. The interns are asked to review manuscripts submitted to the journal along with two senior reviewers. The interns submit their reviews under the same guidelines as the senior reviewers, and receive the other two reviews, as well as updates about the final disposition of the manuscript. This enables the interns to compare and contrast their own comments with the others. If appropriate, the Associate Editor includes an intern's review in the decision letter to the authors.

Accordingly, the Executive Editors of Laboratory Investigation would like to thank the Editorial Interns who have served the journal through 2010, listed below.

Brian Abe

Lingbao Ai

Kathryn Behling

Suzan Commandeur

Gong Feng

Sarah Francis

Paul Furmanczyk
Joy Gibson

Arvin Gouw

Yu Han

Eldad Hod

Yongcheng Huang

Kun Jiang

Karen Kelly

Melissa Landek-Salgado

Sungyul Lee

Ang Li

Yiting Lim

Michael Linden

Qin Liu

Nidia Messias

Sarah Murray

Haitao Niu

Maja Oktay

Rupal Pandey

Alexandros Polydorides

Sadiye Rieder

Michael Rivera

Toni Roberts

Roy Angshumoy

Deborah Sevilla

Heather Stevenson

James Suh

Matthew Titmus

Kimberly Walter

Jianbo Wang

Qinhong Wang

Yutao Yan

Xiangping Yang

Jingsong Yuan 